\title{
Validation of Minimum Display Requirements for a UAS Detect and Avoid System
}

- Presented to:

AIAA Aviation 2017, Denver, CO

\section{JUNE 2017}

Conrad Rorie, San Jose State University

Lisa Fern, San Jose State University

Zach Roberts, San Jose State University

Kevin Monk, NASA Ames Research Center

Confesor Santiago, NASA Ames Research Center

Jay Shively, NASA Ames Research Center 


\section{Background}

- NASA's Unmanned Aircraft Systems Integration into the National Airspace System (UAS in the NAS) Project has been investigating the technical barriers associated with the full integration of UAS into civil airspace

- Its research has been conducted in collaboration with RTCA Special Committee 228 (SC-228), responsible for developing the Minimum Operational Performance Standards (MOPS) for UAS

- SC-228 is made up of experts from government, industry and academia

- Technical focus has been on two critical technology areas identified by the FAA: Command and Control (C2) and Detect and Avoid (DAA)

- DAA MOPS cover the technical requirements for supporting a means of compliance with Title 14 Code of Federal Regulations (14CFR) Part 91, sections $.3, .111, .113(b)$ and $.181(b)$

- In essence, pilots have the authority to "see and avoid" other aircraft to maintain "well clear"

- In manned aviation, well clear is a subjectively-defined separation standard intended to prevent the need for collision avoidance maneuvers

- UAS developers, however, must redesign this function for remote pilots 


\section{Background}

- At a minimum, a DAA system provides a pilot on the ground with electronic information to maintain and regain DAA well clear (DWC)

- Unlike the concept in manned aviation, DWC has been mathematically defined

- The electronic information should help the pilot:

1. Detect potential threats to DWC

2. Determine an appropriate response

3. Execute the evasive maneuver

- A series of human-in-the-loop experiments were conducted to identify the minimum information requirements for a DAA display $(4,5,6,7)$

- Response time data, loss of DAA well clear data and subjective data were all used to help identify the display features most useful for pilots performing the DAA task 


\section{Previous Research}

- Earlier simulations focused on providing the pilots with either Informative or Directive DAA displays $(4,5)$

- Informative DAA displays provide pilots with basic alerting and traffic information

- Directive DAA displays provide pilots with an additional layer of guidance in the form of a single recommended resolution maneuver

- Directive maneuver guidance display configurations were found to lead to faster pilot responses and fewer DWC violations (although the differences were not always statistically significant)

- While Informative displays seemed insufficient, Directive displays were determined to be too difficult to certify as a DAA solution
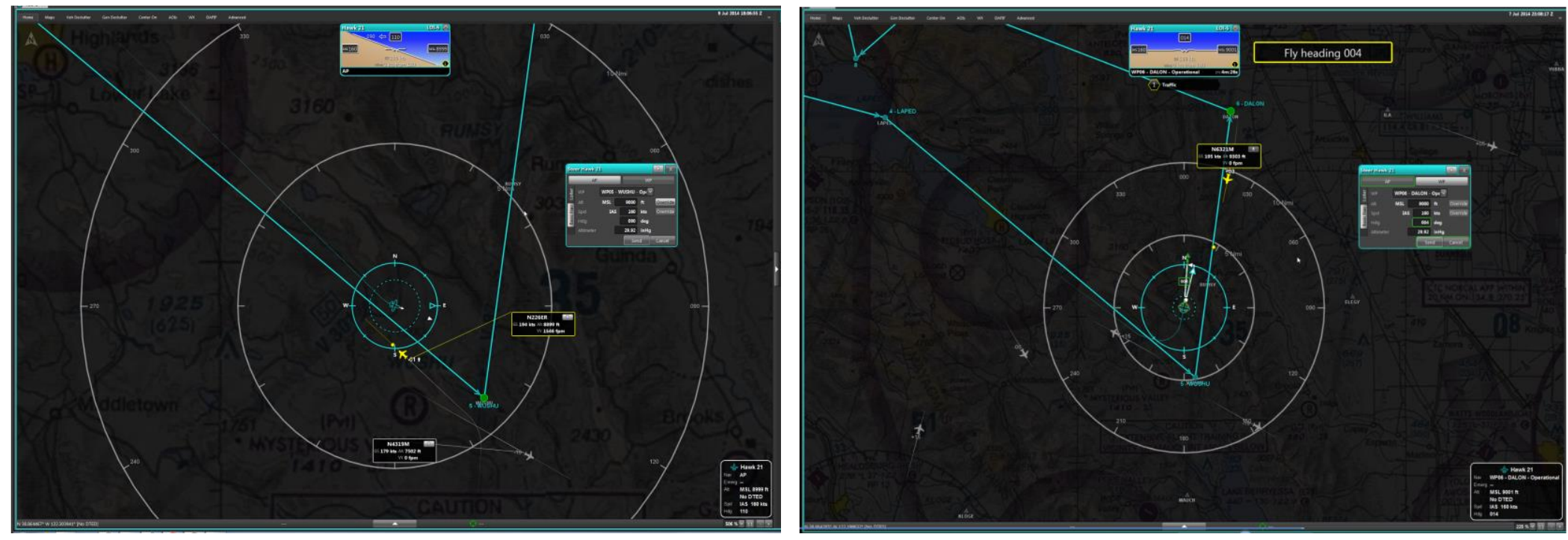


\section{Previous Research}

- The next two HITLs focused on investigating different types of Suggestive DAA displays

- Suggestive DAA displays provide pilots with a range of solutions, leaving it up to the pilot to make the ultimate decision

- Provides more guidance than Informative displays but easier to certify than Directive displays

- The most effective type of Suggestive DAA display that was tested was "banding," which used dynamic and constantly-available color-coded arcs to show the threat level associated with nearby headings and altitudes

- Proved more effective than an Informative display and a different Suggestive display tool that required direct pilot interaction
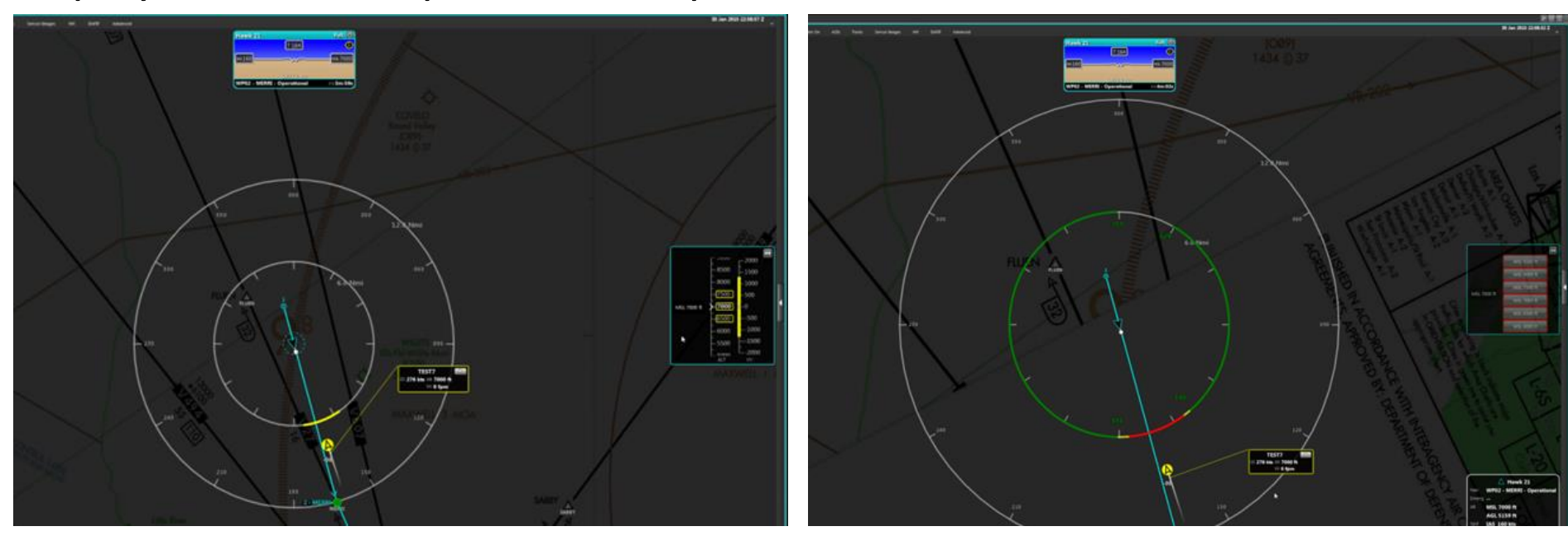


\section{Purpose}

- By the last of the first four HITLs, suggestive DAA maneuver guidance was identified as a minimum requirement

- It also highlighted the need for secondary maneuver guidance for when a loss of DWC cannot be avoided (without which the pilot has no positive guidance)

- The current study was the last in a series of human-in-the-loop experiments designed to identify the minimum information requirements for a DAA display

- Served to validate the alerting and display requirements as specified in the DAA MOPS

- Traffic information available in earlier studies but not in draft version of DAA MOPS was removed here (e.g., call sign, absolute altitude, ground speed, vertical rate)

- Unlike earlier experiments, we did not vary the type of DAA information provided to pilots

- Instead, the performance was compared to earlier studies that did not directly conform to the DAA MOPS

- Two display configurations were tested: Integrated and Standalone

- Both allowable under the DAA MOPS 


\section{Method}

- Experimental Design

- Display Configuration (within-subjects)

- Integrated DAA display - all DAA information presented within primary navigation and control display (i.e., tactical situation display - TSD)

- Standalone DAA display - all DAA information presented within a separate, bootstrapped display, which contained no navigation information or control interfaces

- Threat Type at First Alert (embedded)

- Corrective- caution-level alert when first detected by the DAA system

- Warning - warning-level alert when first detected by the DAA system

- Participants

- 16 active duty UAS pilots

- Average Age: 30

- Average hours of UAS military experience: 600

- Average hours of UAS experience in civil airspace: 60

- 2 active National Air Traffic Controllers Association (NATCA) controllers

- Served as confederates 


\section{Method}

\section{Integrated \\ Configuration}

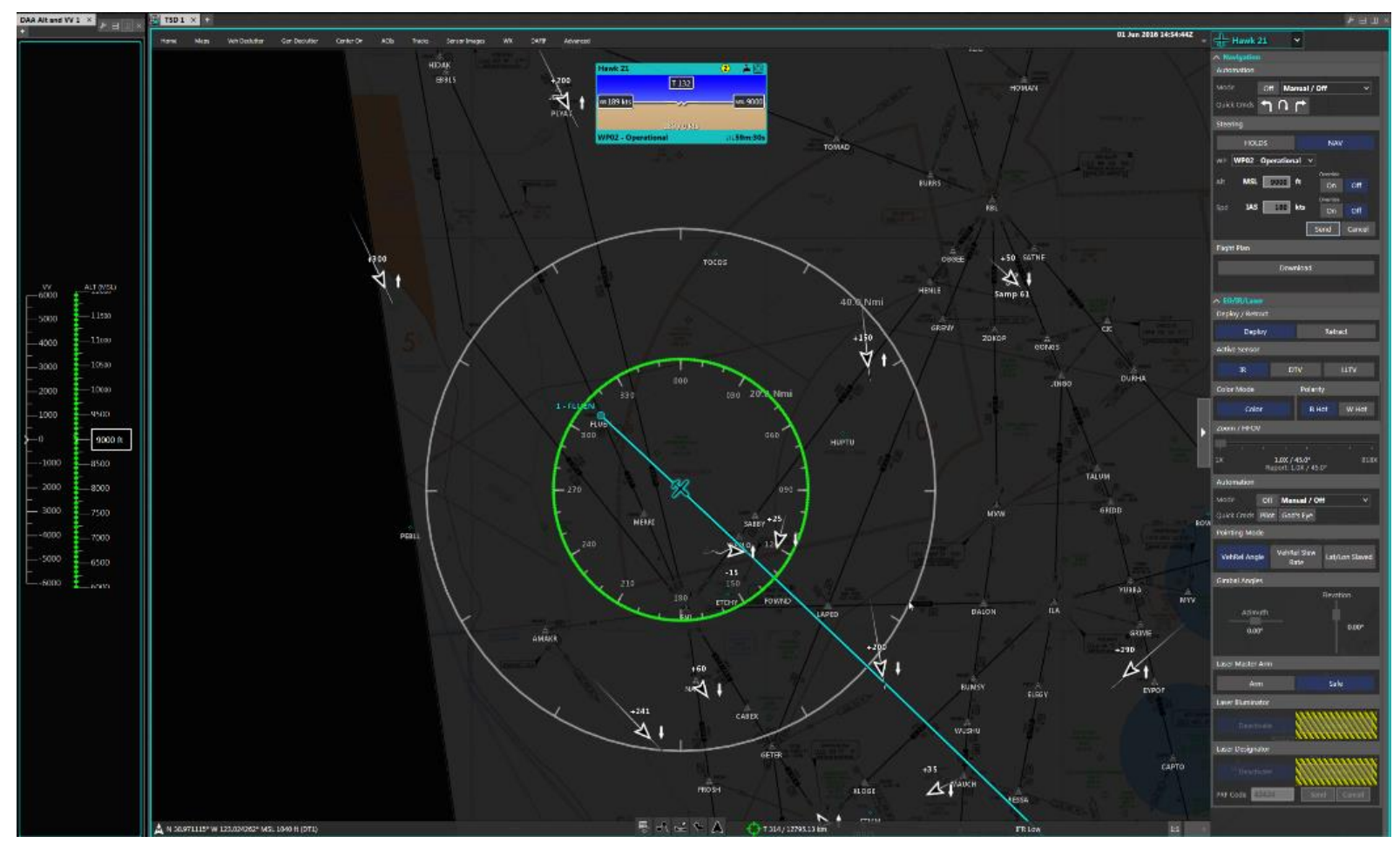

Tactical Situation Display (TSD)

- Navigation information

- Vehicle control interfaces

- DAA information

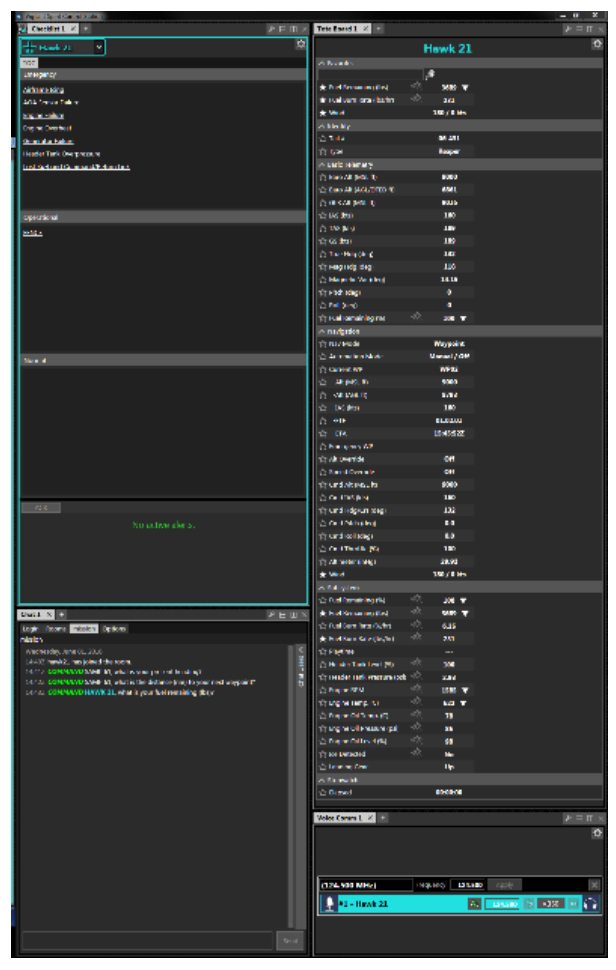

Side Panel

- Telemetry information

- Chat client 


\section{Method}

\begin{tabular}{|c|c|c|c|c|c|}
\hline Icon & Alert Level & $\begin{array}{c}\text { Expected Pilot } \\
\text { Response }\end{array}$ & $\begin{array}{c}\text { Buffered Well Clear } \\
\text { Criteria }\end{array}$ & $\begin{array}{c}\text { Time to Loss of } \\
\text { Well Clear }\end{array}$ & $\begin{array}{c}\text { Aural Alert } \\
\text { Verbiage }\end{array}$ \\
\hline & $\begin{array}{c}\text { DAA Warning } \\
\text { Alert }\end{array}$ & Maneuver immediately & $\begin{array}{c}\text { HMD }=0.75 \mathrm{~nm} \\
\text { ZTHR }=450 \mathrm{ft} \\
\text { modTau }=35 \mathrm{sec}\end{array}$ & $\begin{array}{c}\text { "Traffic, } \\
\text { Maneuver } \\
\text { Now" }\end{array}$ \\
\hline x 25
\end{tabular}




\section{Method}

- JADEM Omni Bands served as suggestive maneuver guidance

- Headings 'bands' appear on the inner range ring

- Altitude 'bands' appear to the far left of the TSD

- Bands updated constantly to reflect current threat level for range of headings/altitudes

\section{Altitude Bands}

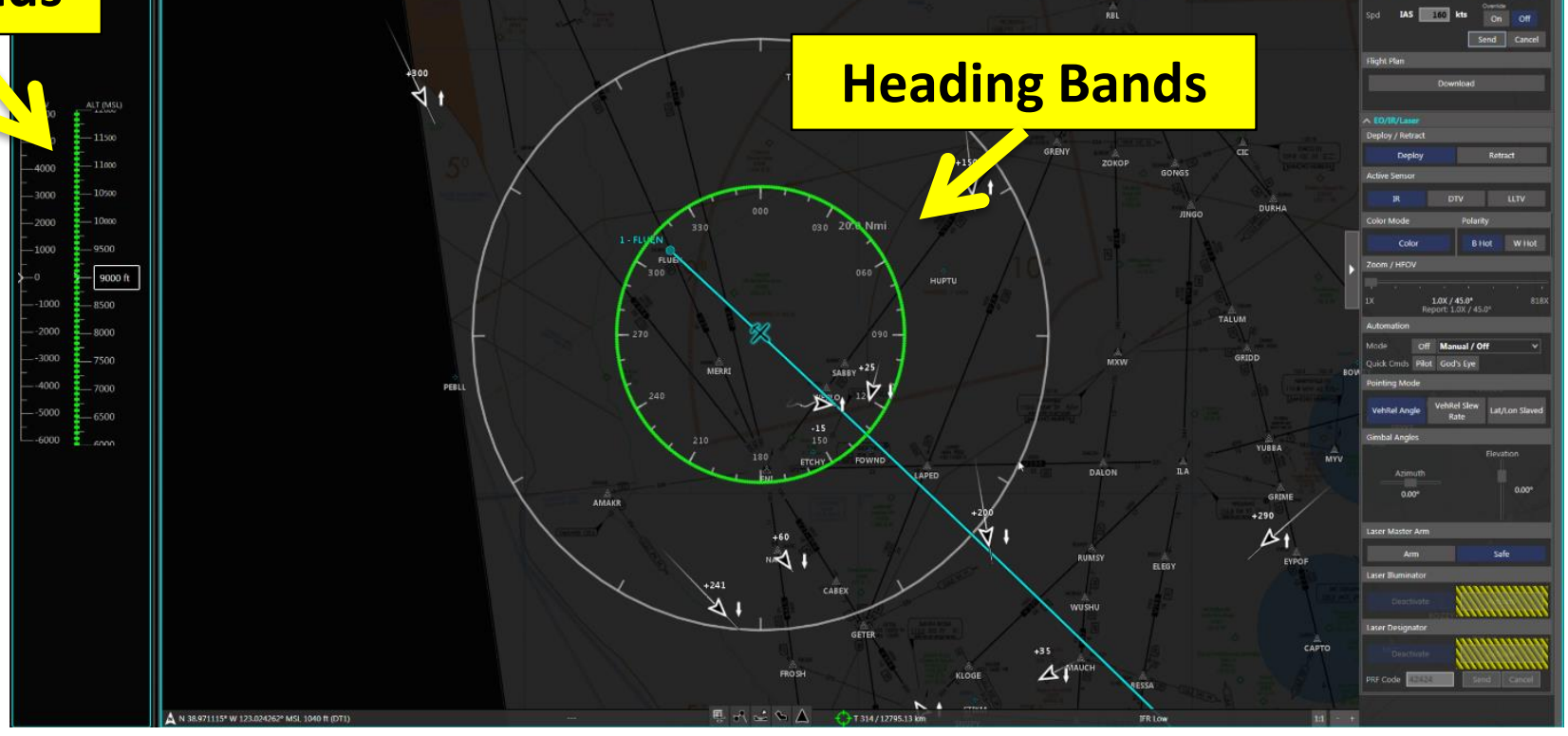




\section{Method}

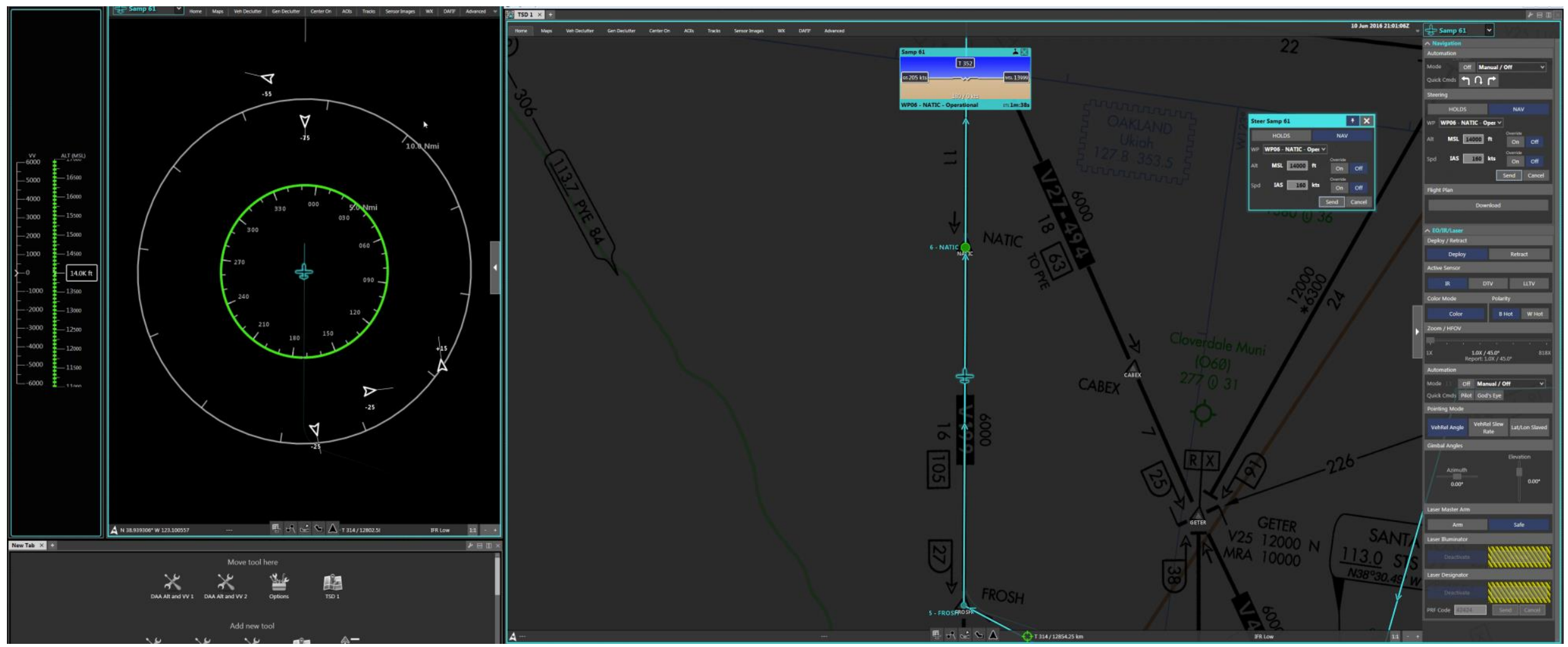




\section{Method}

- If algorithm determines horizontal maneuver will lead to greatest separation:

- Shown optimal heading region ("wedge") to fly next to ownship

- If algorithm determines vertical maneuver will lead to greatest separation:

- Green altitude block ("wedge") within altitude tape shows optimal altitude range

- Vertical WCR never provided against cooperative intruders

NOTE: No aural alert at this stage

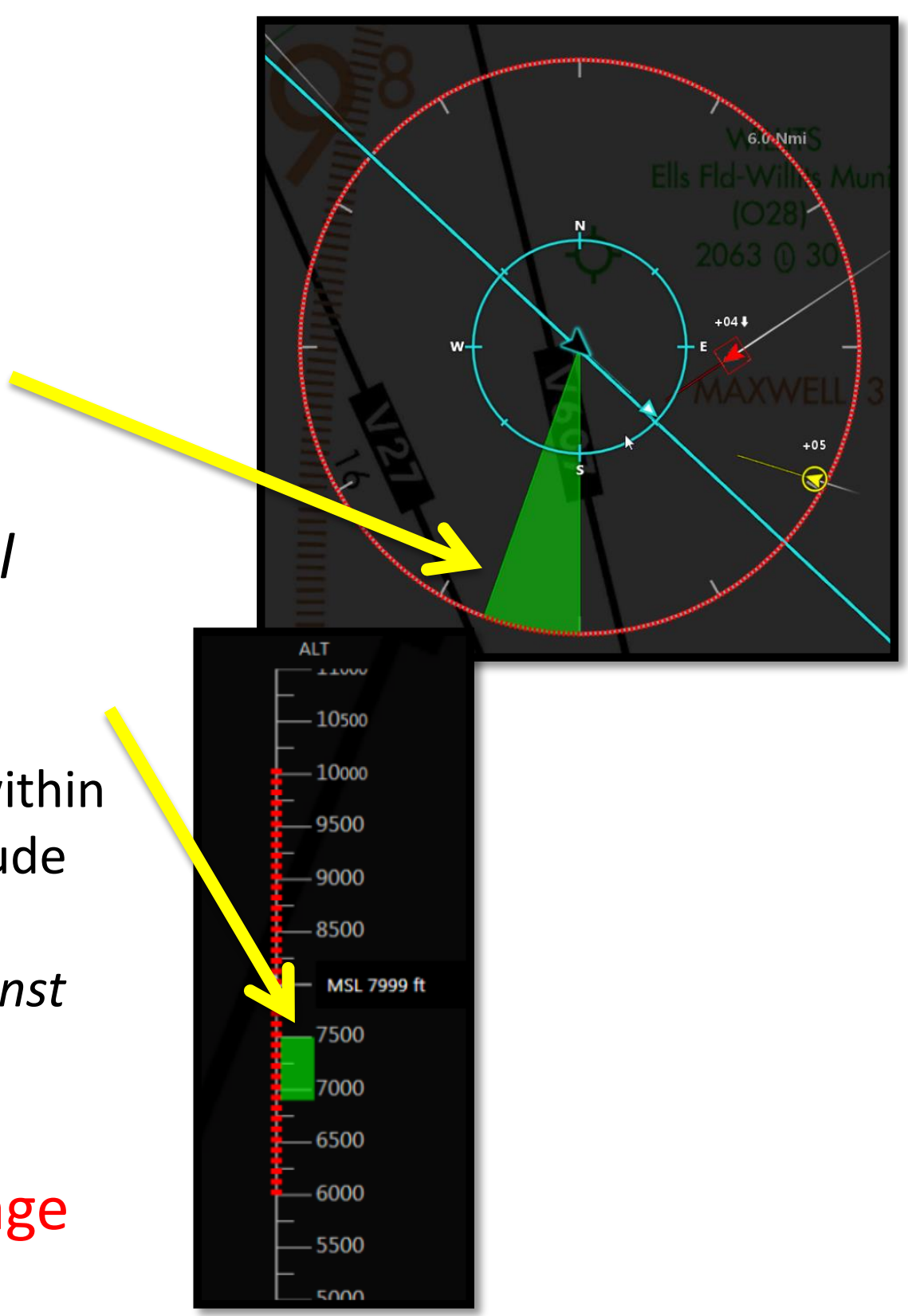




\section{Method}

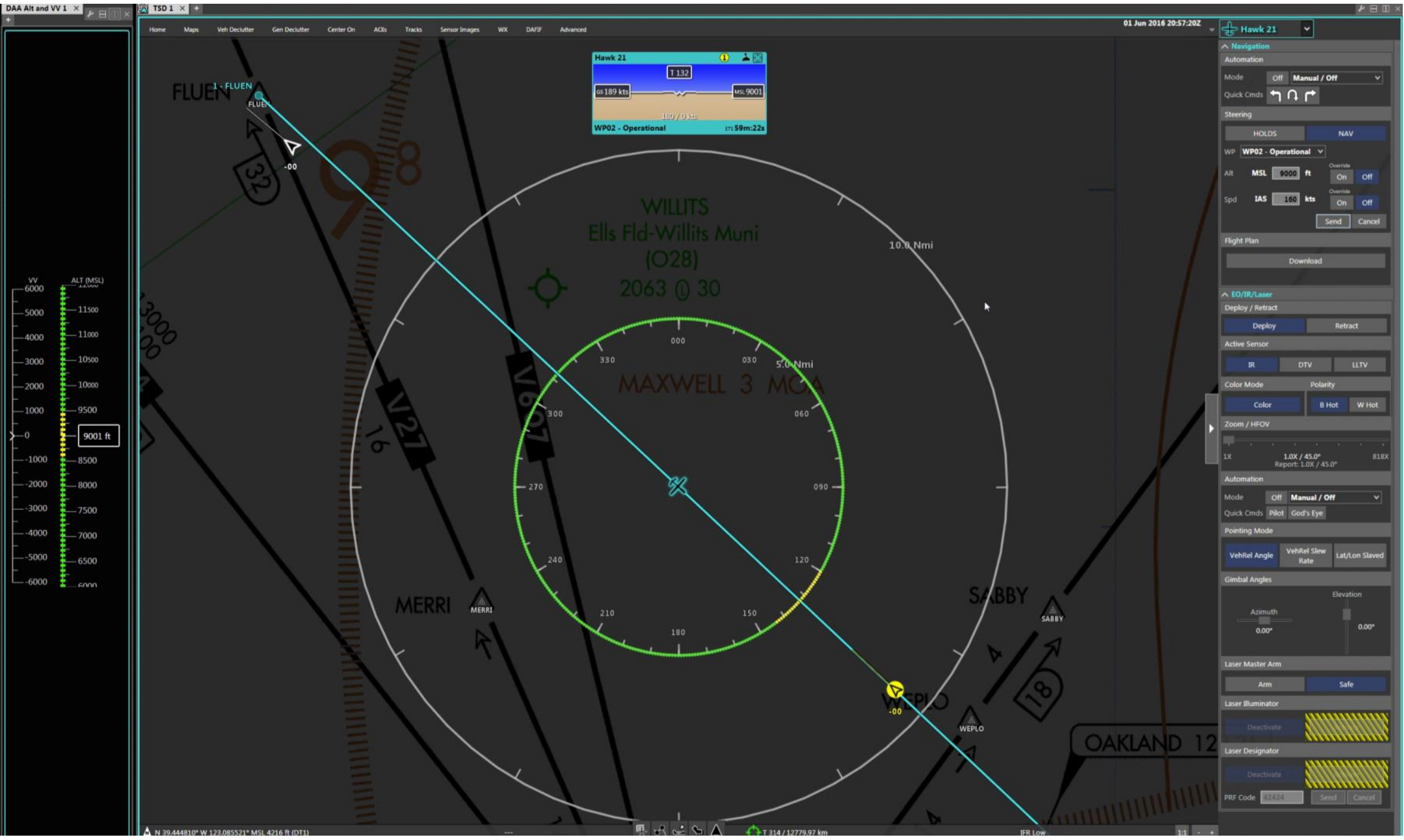




\section{Procedure}

- Task:

- Fly simulated MQ-9 through Class E airspace (Oakland Center - ZOA 40/41)

- Navigate along pre-filed routes (used AFRL's Vigilant Spirit Control Station)

- 2 different routes flown (HAWK21 \& SAMP61)

- Attend to secondary tasks (e.g., chat messages, system alerts)

- Maintain well clear

- Coordinate with ATC (time permitting)

- Pre-planned conflicts with ownship

- 6 scripted encounters predicted to lose well clear designed to address major functional areas of DAA:

- Multi-threat (1 coop \& 1 non-coop)

- Blunder-causing DAA Warning

- High speed encounter

- Vertical transitioning encounter

- Ownship in climb/descent

- Preventive DAA alerts 


\section{Procedure}

- Simulation Hardware/Software:

- Vigilant Spirit Control Station (VSCS) from AFRL

- 2 instances run simultaneously, each with a different UAS mission route

- Perfect surveillance data (no uncertainty models applied but did have representative sensor ranges)
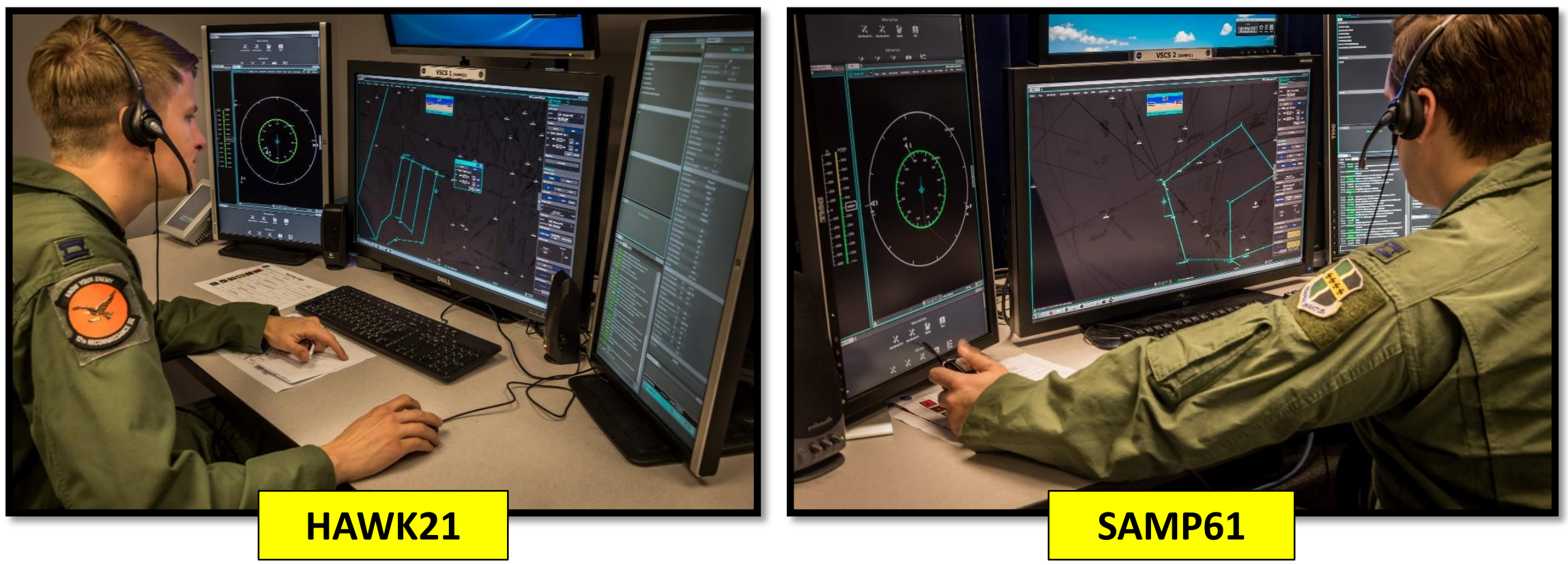


\section{Scenarios}

- Mission routes located within Oakland Center (ZOA40/41)

- Both mission routes operated with Oakland Center airspace

- Includes a variety of classes of airspace

- IFR traffic into and out of SFO and OAK

- VFR traffic from smaller airports (e.g., STS and APC)

Sector 40/41-Surrounding Facilities and Sectors

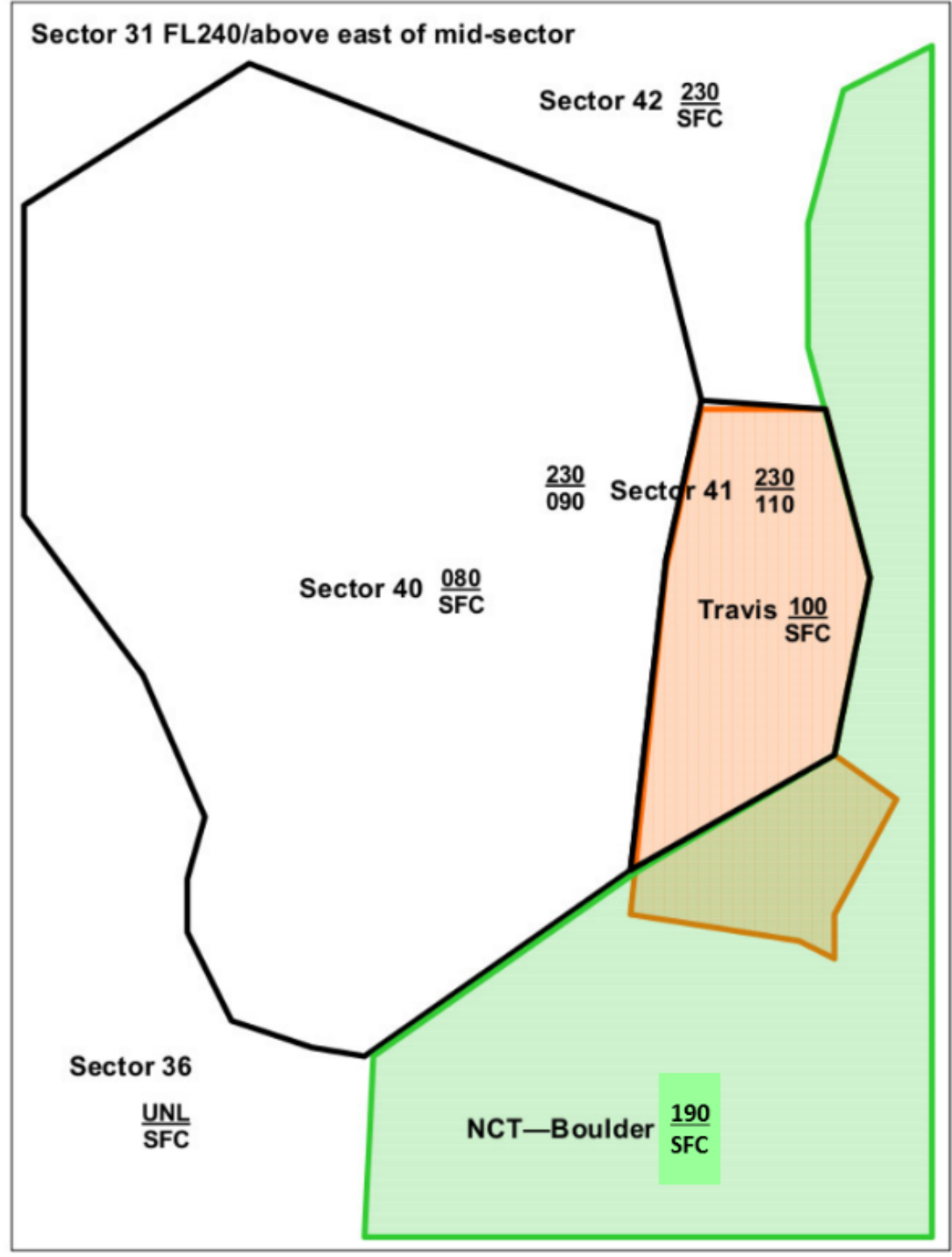




\section{Scenarios}

- Fire Line Track (HAWK21)

- Level at 9000'

- Serving as air asset for California Department of Forestry for fire burning north of Clear Lake

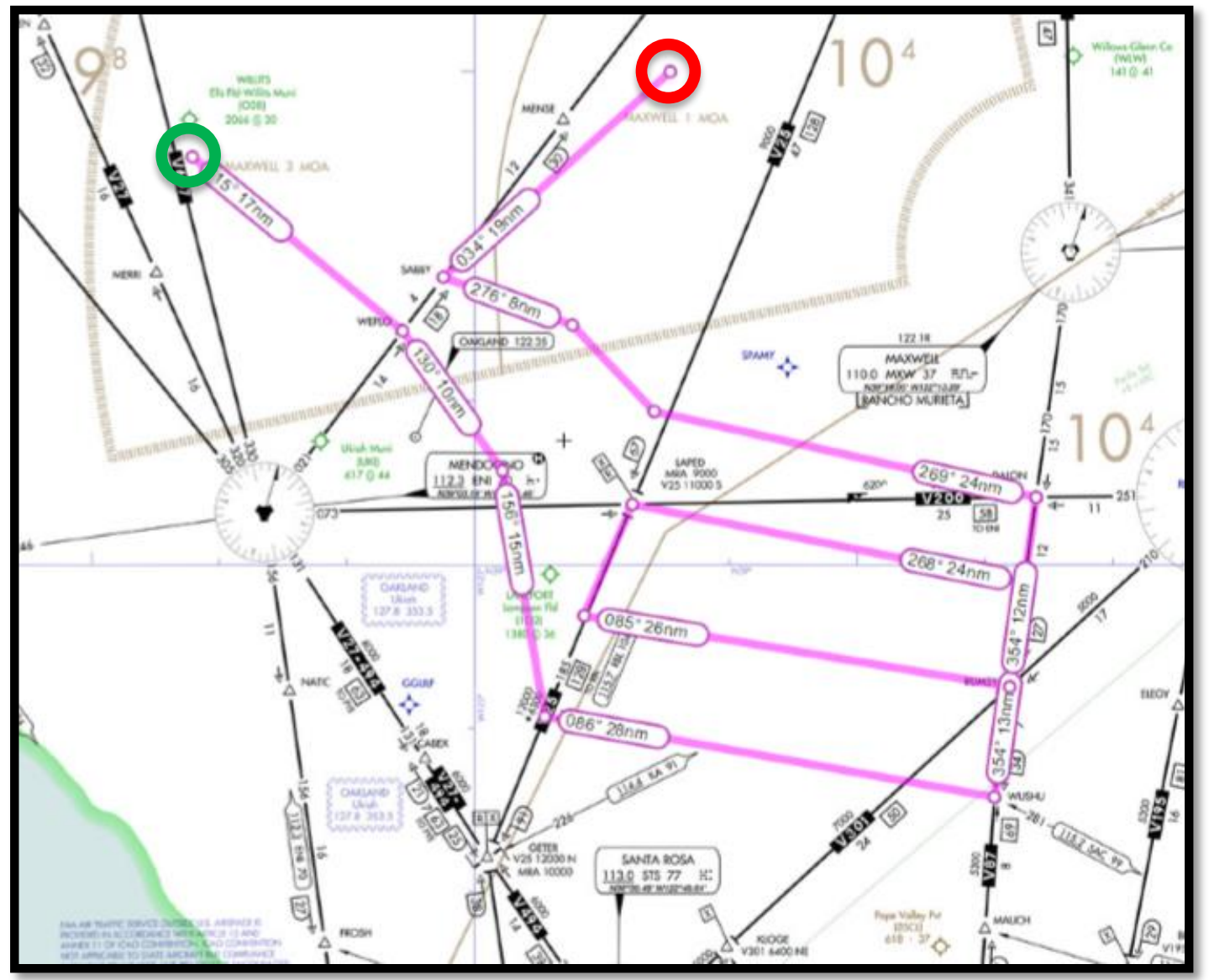




\section{Scenarios}

- Air Sampling Track (SAMP61)

- Starts at 10000', contains climb \& descent

- Serving as air asset for California Air Resources Board to measure quality of air east of Santa Rosa

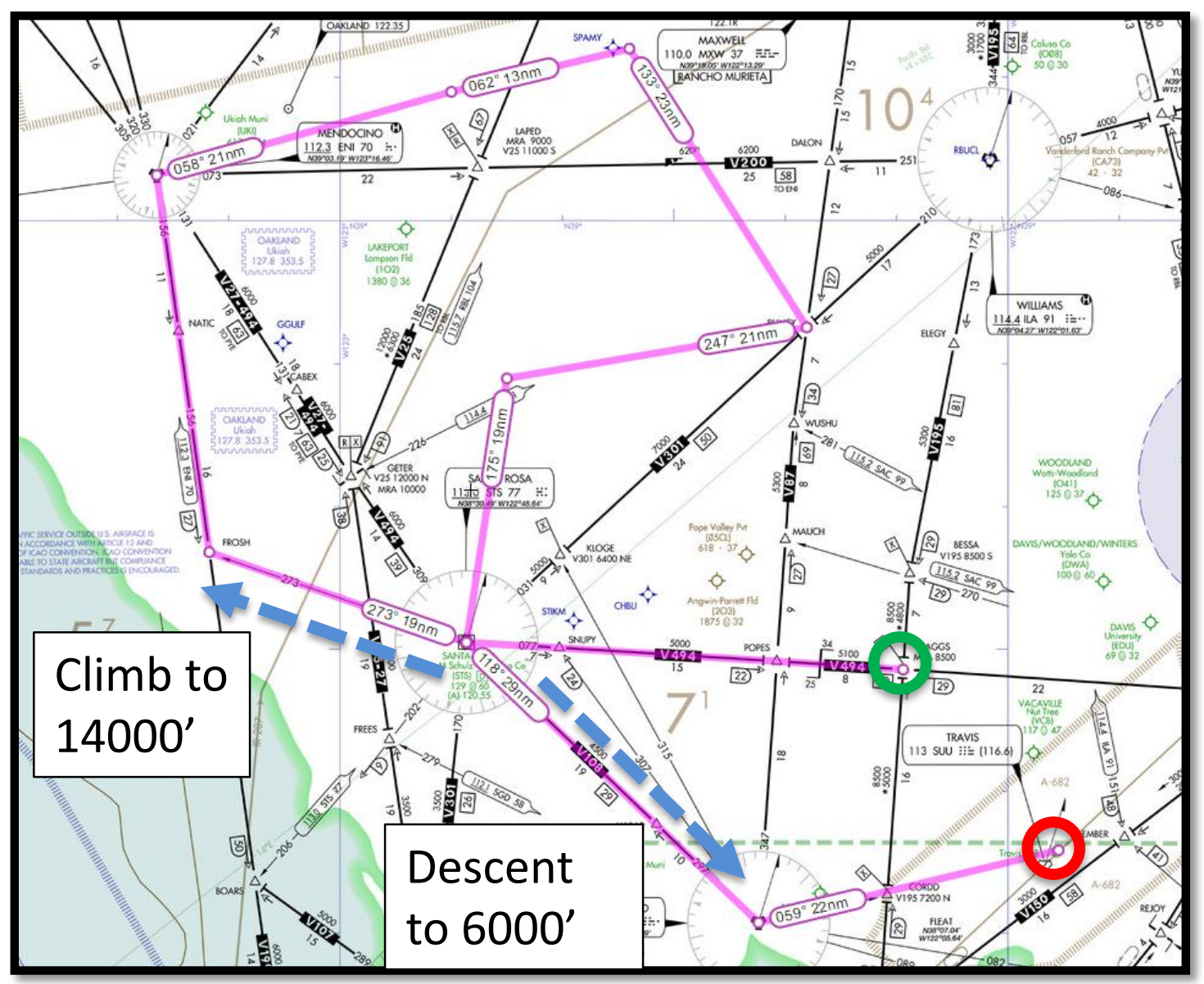




\section{Procedure}

- Simulation confederates

- NATCA controller managed UAS and manned traffic within ZOA 40/41

- Simulated manned traffic based on actual sector activity

- Pseudo-pilots managed all manned traffic to provide dynamic sector activity

- ATC SME operated as 'ghost' controller to ensure conflicts were generated

- HSI researcher operated VSCS internal conflict generator

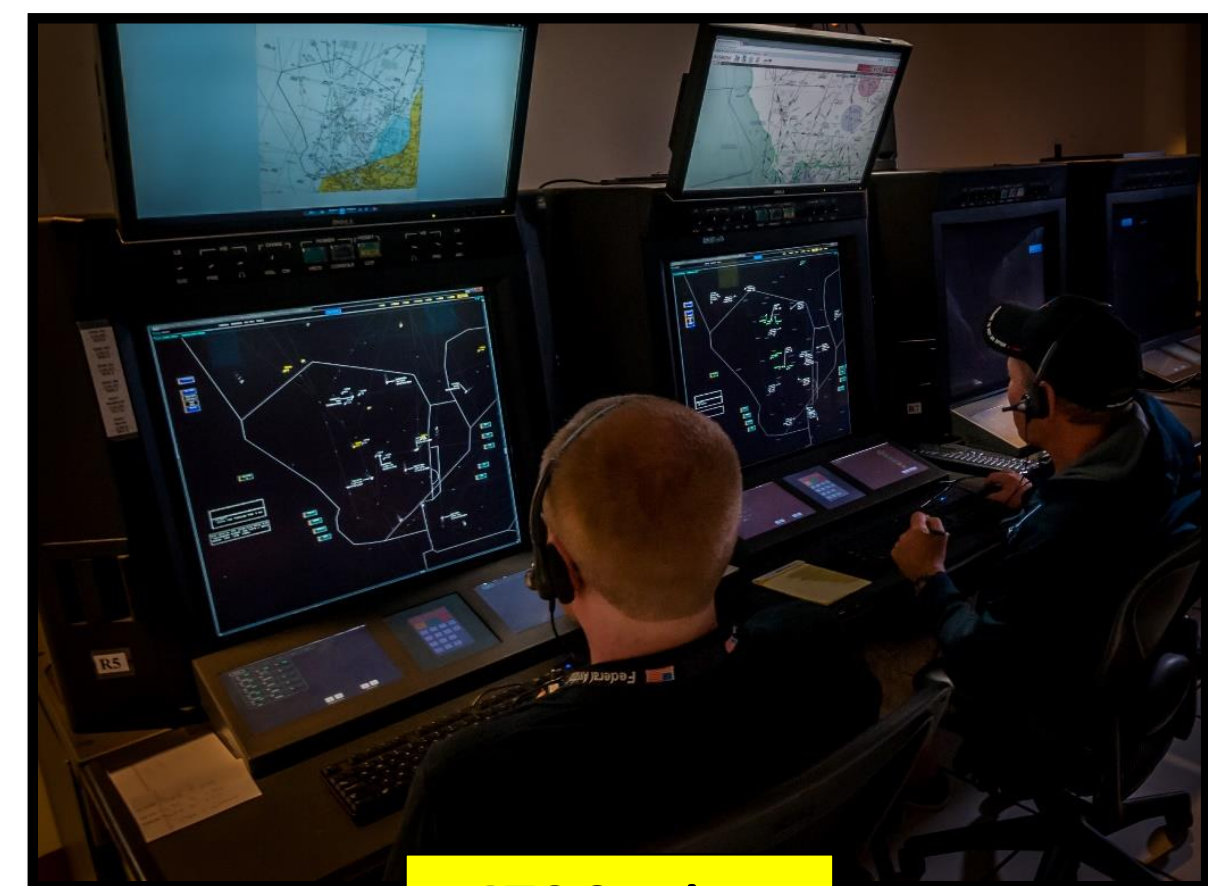

ATC Station

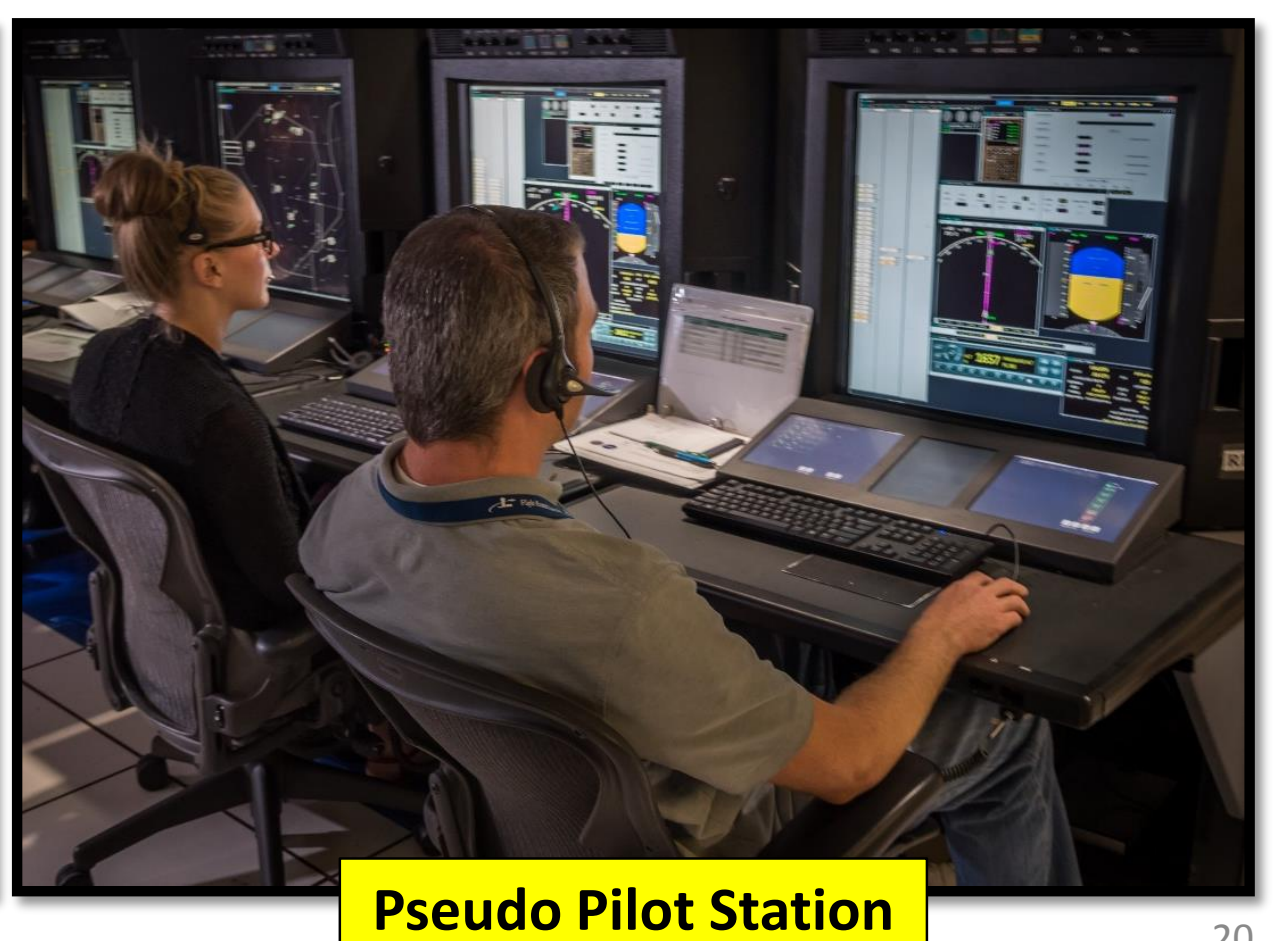




\section{Research Questions}

- Primary:

- Is pilot performance with minimum display requirements (as currently defined in the draft MOPS) comparable to previous simulations?

- Secondary:

- Any impact of the display configuration variable (Standalone vs. Integrated)?

- What effect did threat type at first alert have on performance (Caution vs. Warning)?

- Metrics

- Measured Response

- Initial response time - time to initiate a response to a detected threat

- Edit time - time spent interacting with vehicle control interfaces

- Aircraft response time - total time to send first upload to aircraft (initial + edit response time)

- Separation Metrics

- Proportion of Loss of DWC - rate of loss of DWC out of those predicted to lose separation

- Loss of DWC severity - proportion of the DWC volume the intruder penetrated

- Loss of DWC categorization - cause of the loss of DWC 
RESULTS 


\section{Measured Response}

- Significant main effect of display configuration on aircraft response times

- Difference of $1.3 \mathrm{sec}$

- Warning alert associated with $\sim 8 s e c$ reduction

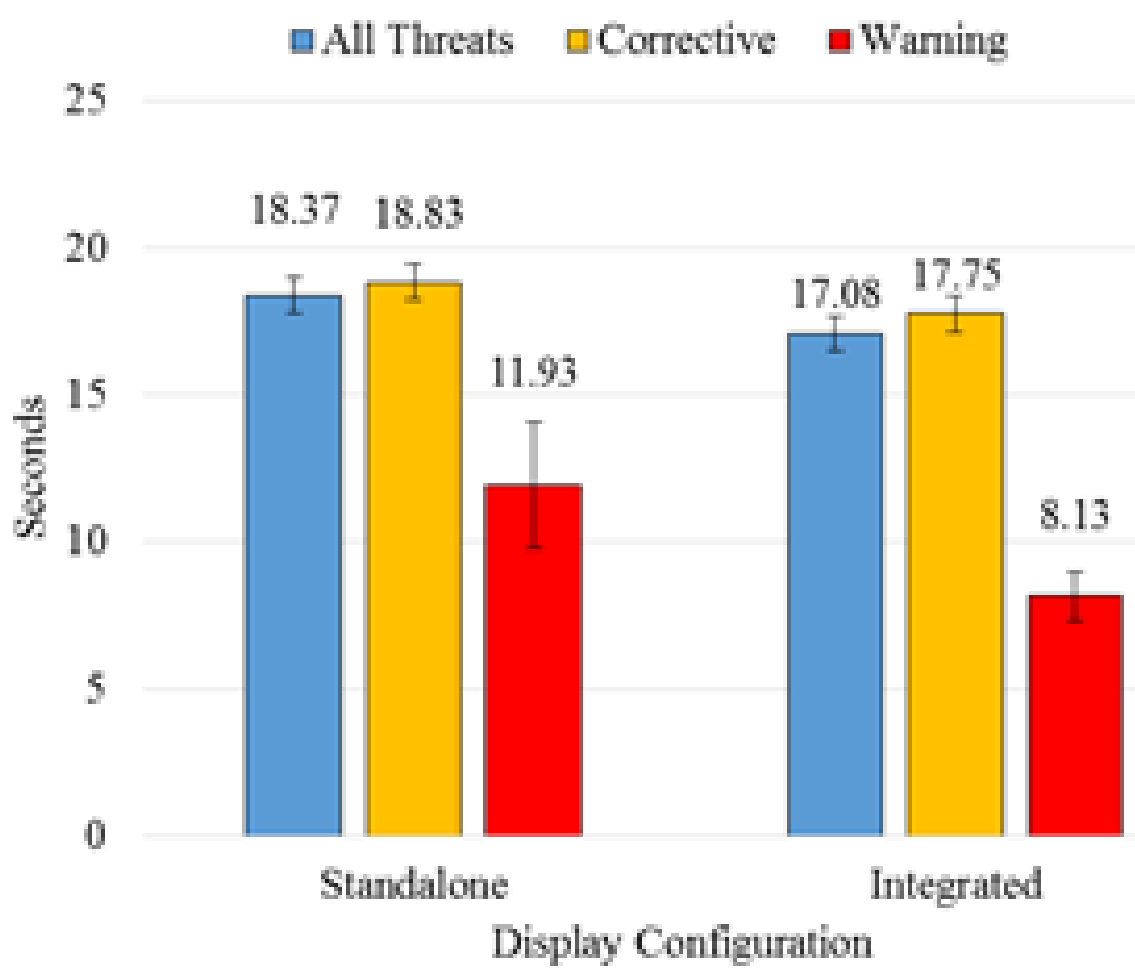

Aircraft Response Time 


\section{Measured Response}

- Source of reduction in aircraft response times a result of faster initial responses (not shorter edit times)

- Integrated condition associated with $1.4 \mathrm{sec}$ faster initial response times but $0.2 \mathrm{sec}$ slower edit times

- Warning alerts had larger effect on initial response times ( $\sim \mathrm{sec})$ than edit times $(\sim 2 \mathrm{sec})$
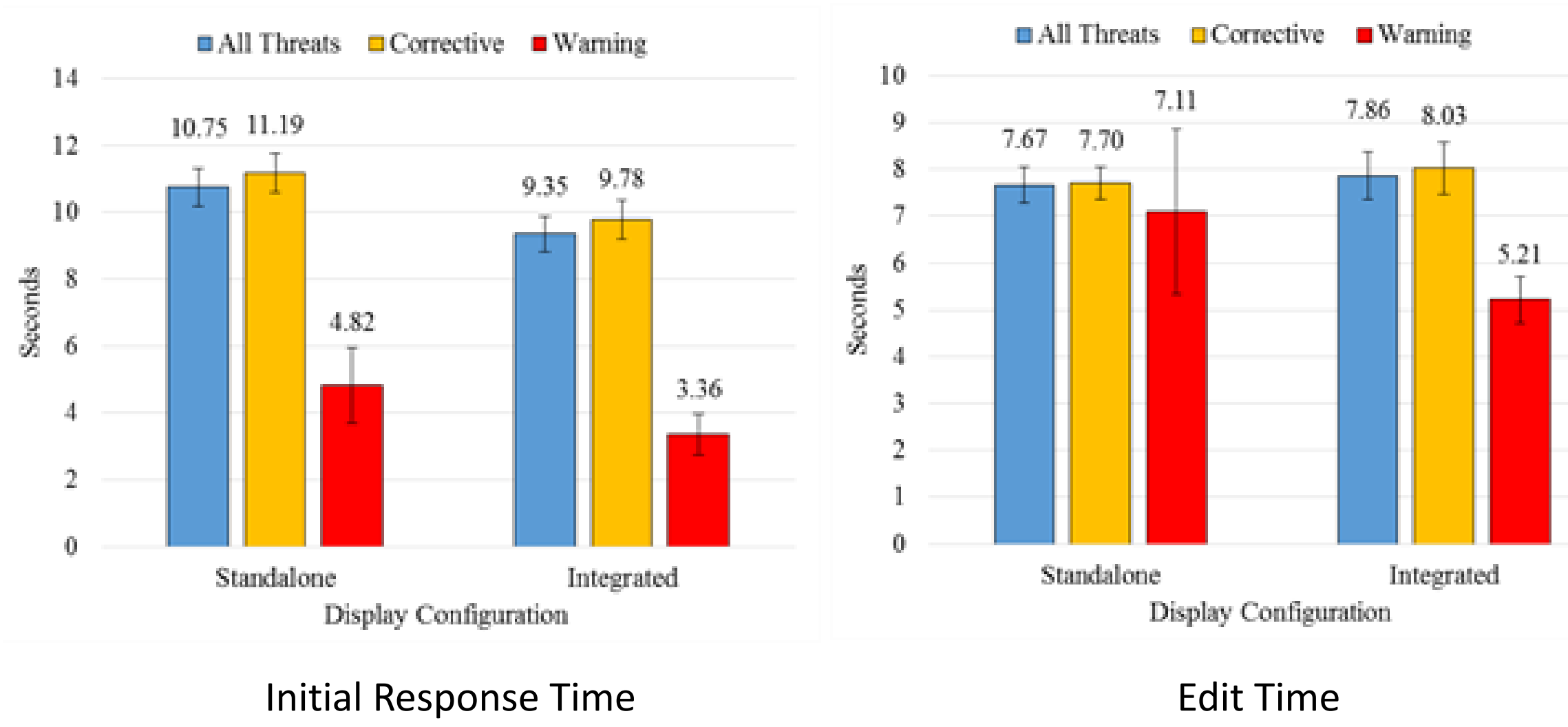

Initial Response Time

Edit Time 


\section{Measured Response}

- Aircraft response times compare favorably to most recent HITL (Part Task 5)

- Both display configurations in current study associated with shorter responses to caution-level alert

- Integrated condition associated with shorter responses to warning-level alert

Part Task 5 (2015)

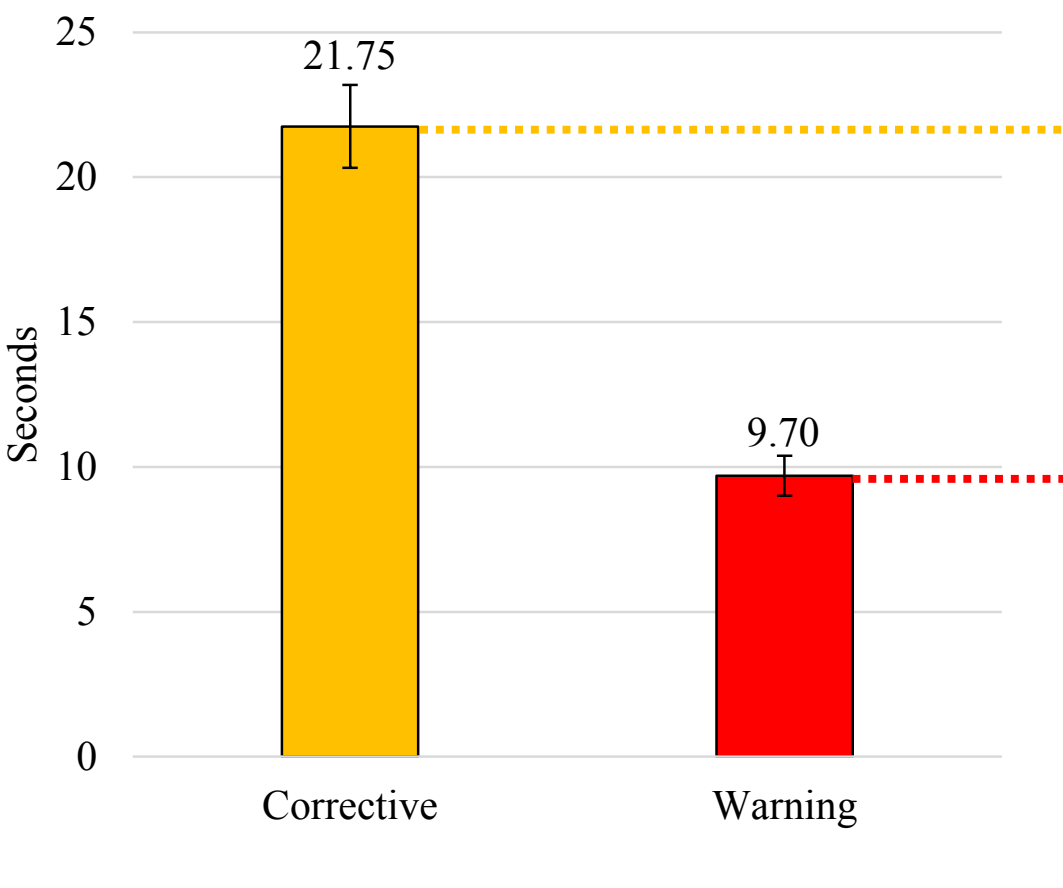

Part Task 6 (Current Study)

25

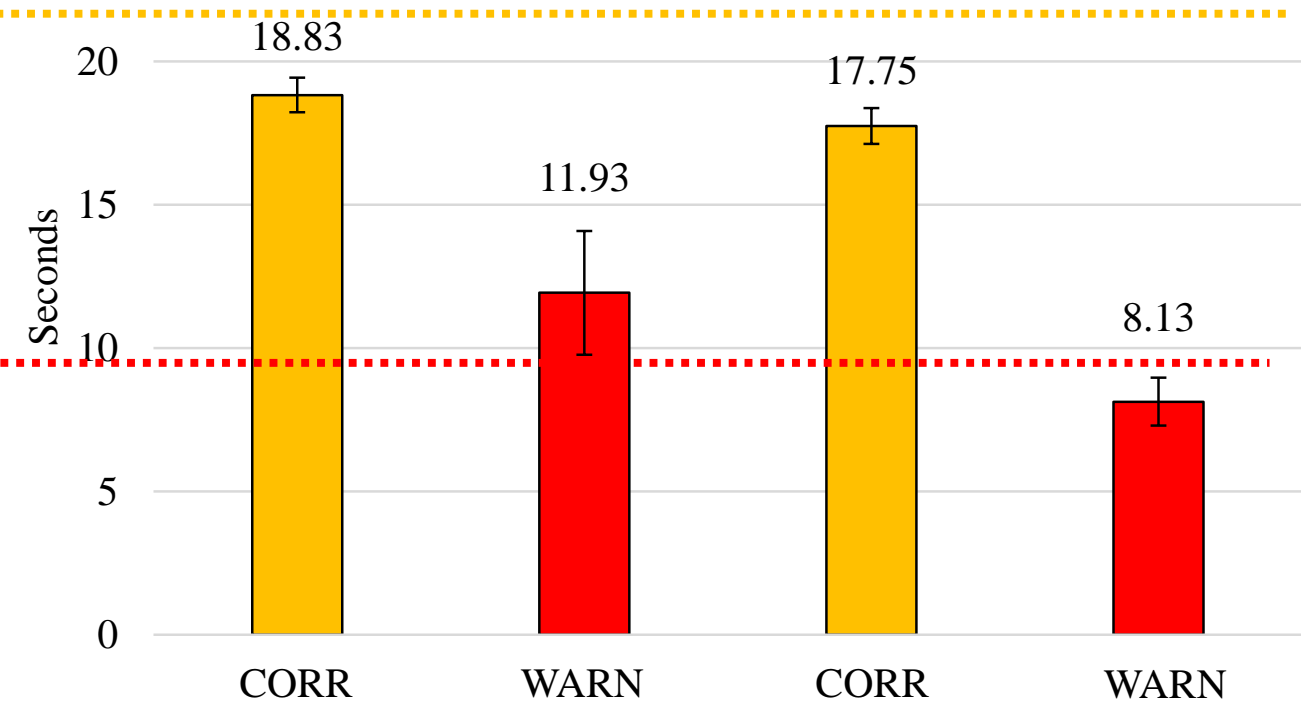

Standalone

Integrated 


\section{Loss of DAA Well Clear Proportion}

- All encounters (Corrective \& Warning at first alert):

- 16 total LoDWC (out of 466 total encounters; $=3 \%$ )

- Standalone $=9$ total LoWC

- Integrated = 7 total LoWC

- Not significantly different

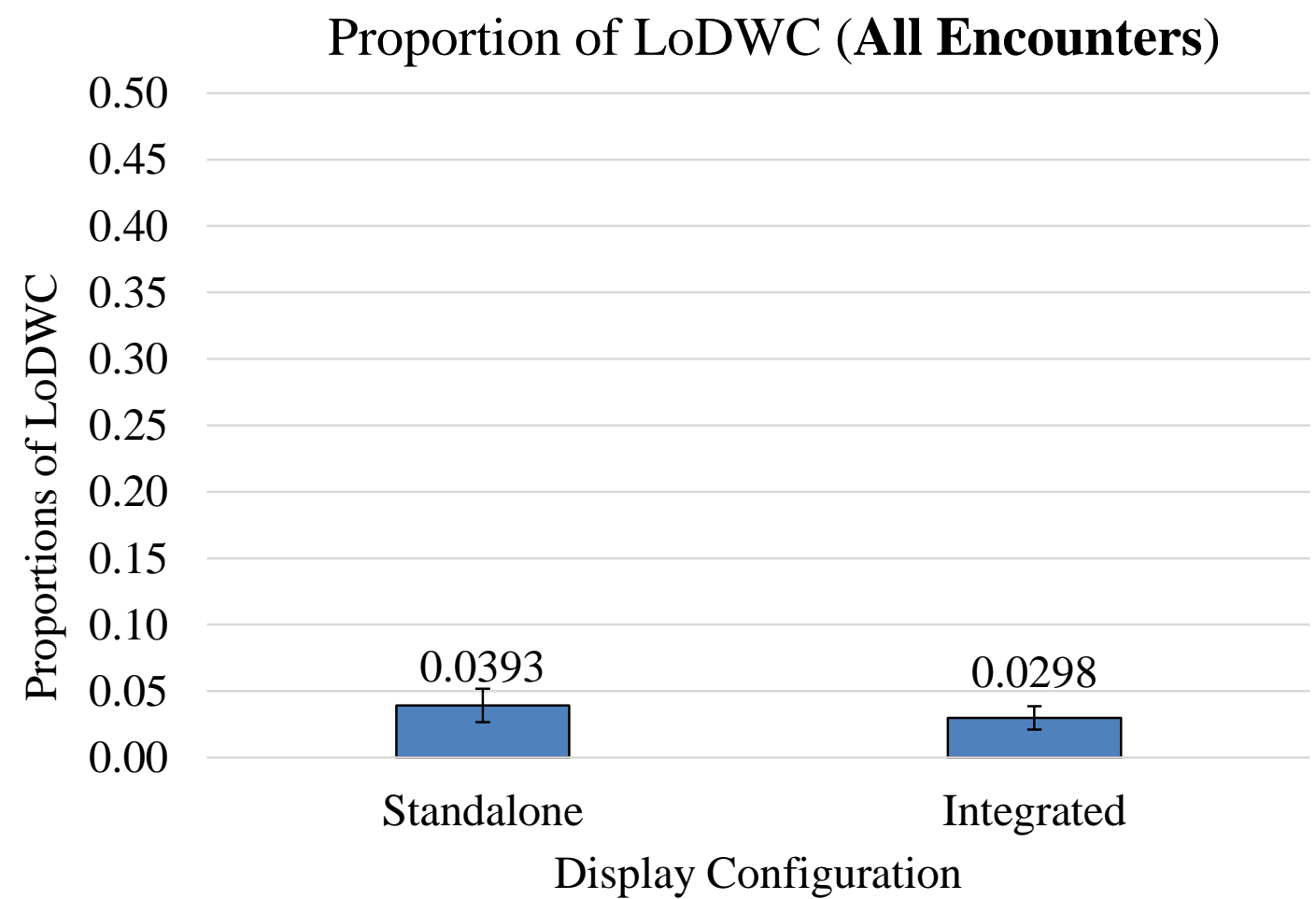




\section{Loss of DAA Well Clear Proportion}

- LoDWC most common with less than $25 \mathrm{sec}$ to loss of well clear at time of first alert

- One encounter was scripted to make 90deg turn into ownship late into problem to force appearance of well clear recovery

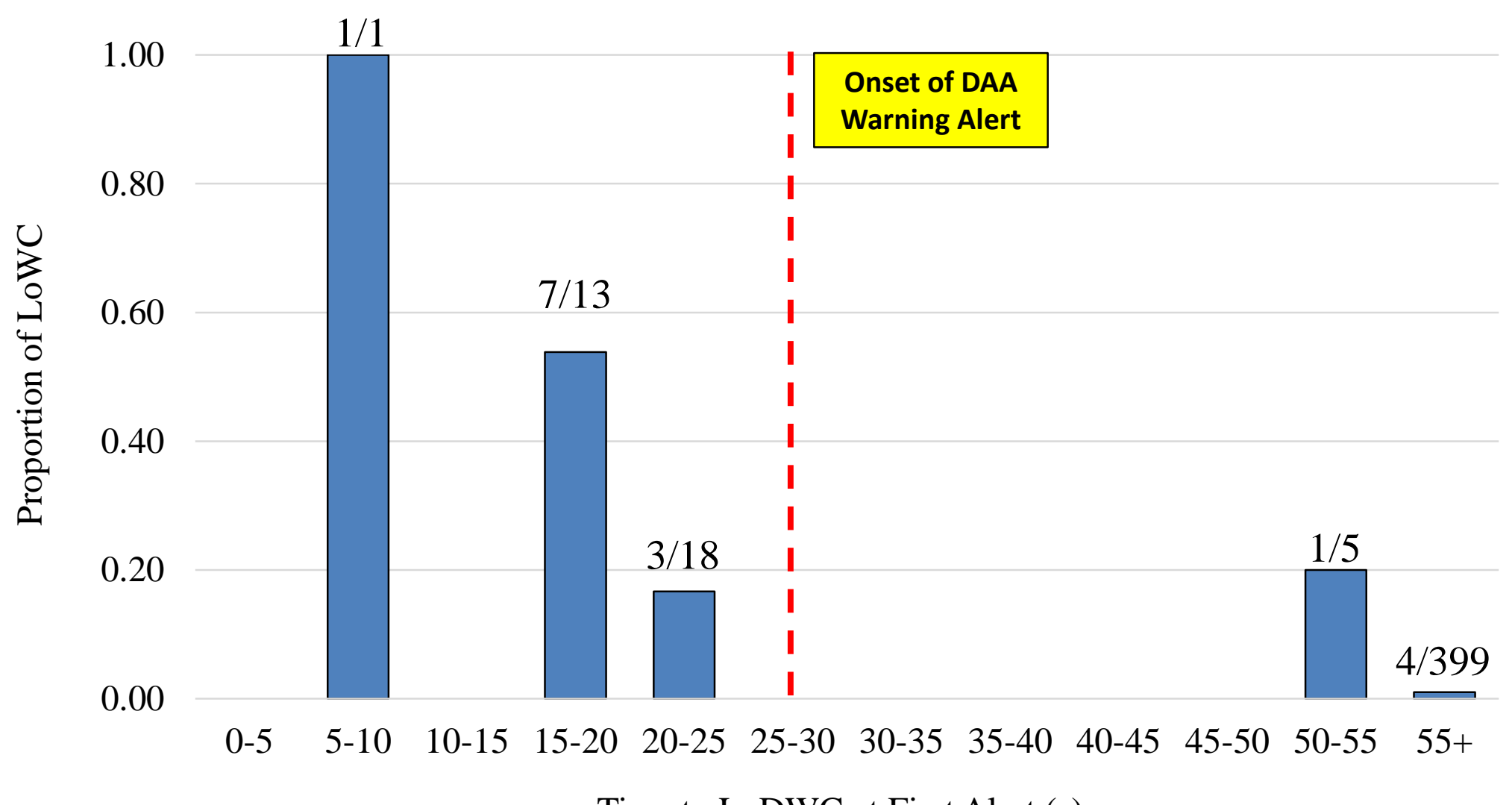

Time to LoDWC at First Alert (s) 


\section{Diagnosing Losses}

- 11 occurred as a result of having less than $25 \mathrm{sec}$ to a loss of DWC

- Remaining 5 LoWC when intruder was Corrective at First Alert

- Standalone (4 LoWC)

- 1 instance had a mismatched between DAA and TSD display orientations

- 2 instances where pilot made ineffective heading changes

- Separate displays may have made it harder for pilot to determine necessary maneuver size

- Also failed to notice bands had changed by time upload sent

- 1 instance where pilot failed to notice altitude bands were no longer threatfree by time upload was made

- Integrated (1 LoWC)

- 1 instance where pilot failed to notice altitude bands were no longer threatfree by time upload was made 


\section{LoWC Severity}

- LoWC Severity (SLoWC) higher in Standalone condition, but still low overall

- SLOWC $=\%$ penetration of well clear (higher = greater penetration)

- Mean for both display configurations $<10 \%$

- No single LoWC exceeded $30 \%$ penetration

- Pilots likely benefited from guidance to regain DAA well clear

- Cannot be compared to previous study since first time this metric has been used

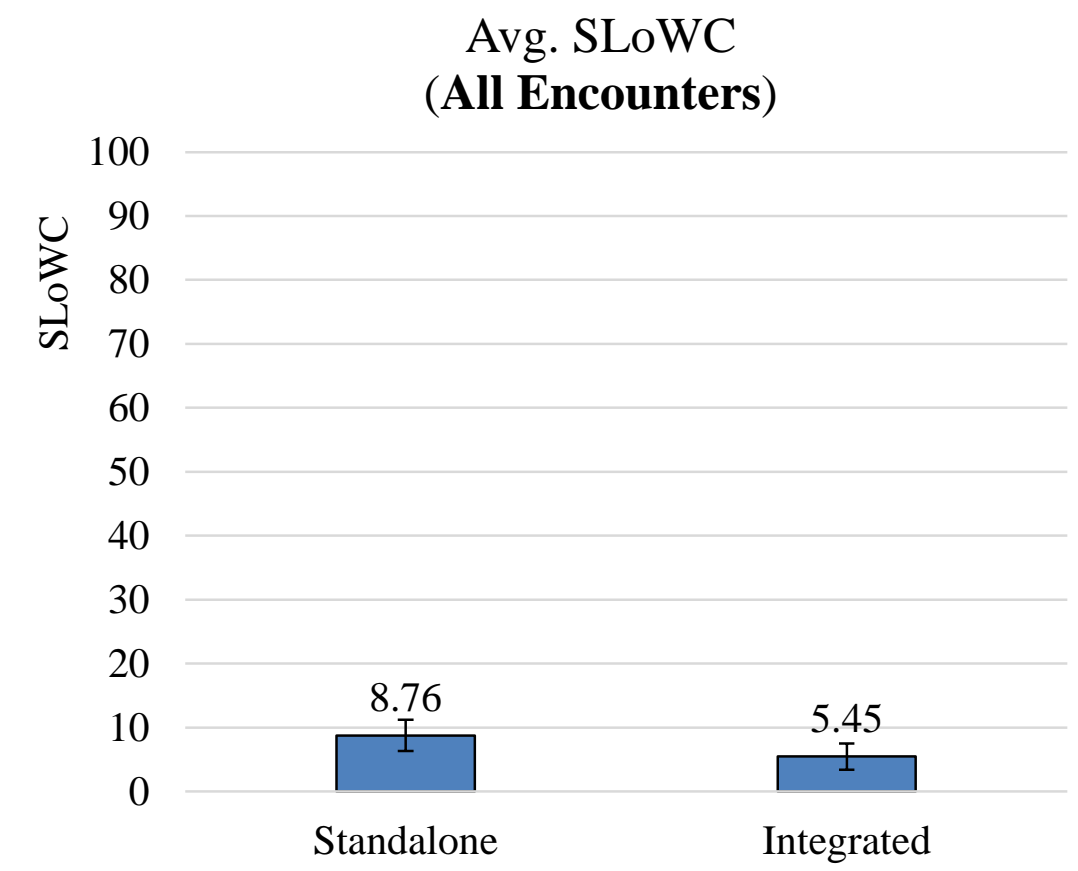

Display Configuration

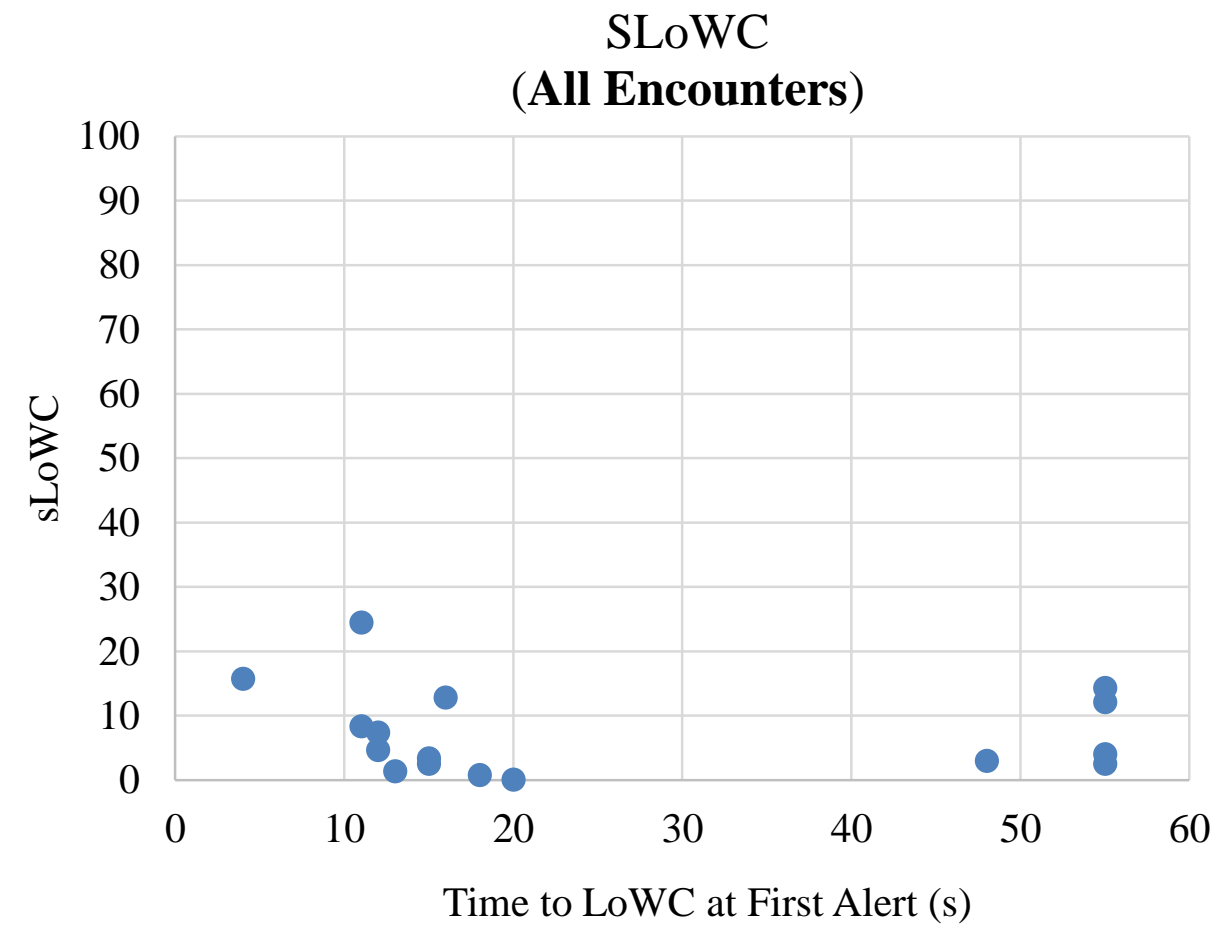




\section{ATC Coordination}

- Pilot consistently received approval from ATC prior to maneuvering away from their mission route for Corrective alert

- Much less common (as expected) in response to Warning alerts

- Pilots received approval to return to course consistently across all conditions

Proportion of Initial Maneuvers with ATC Approval

1.00

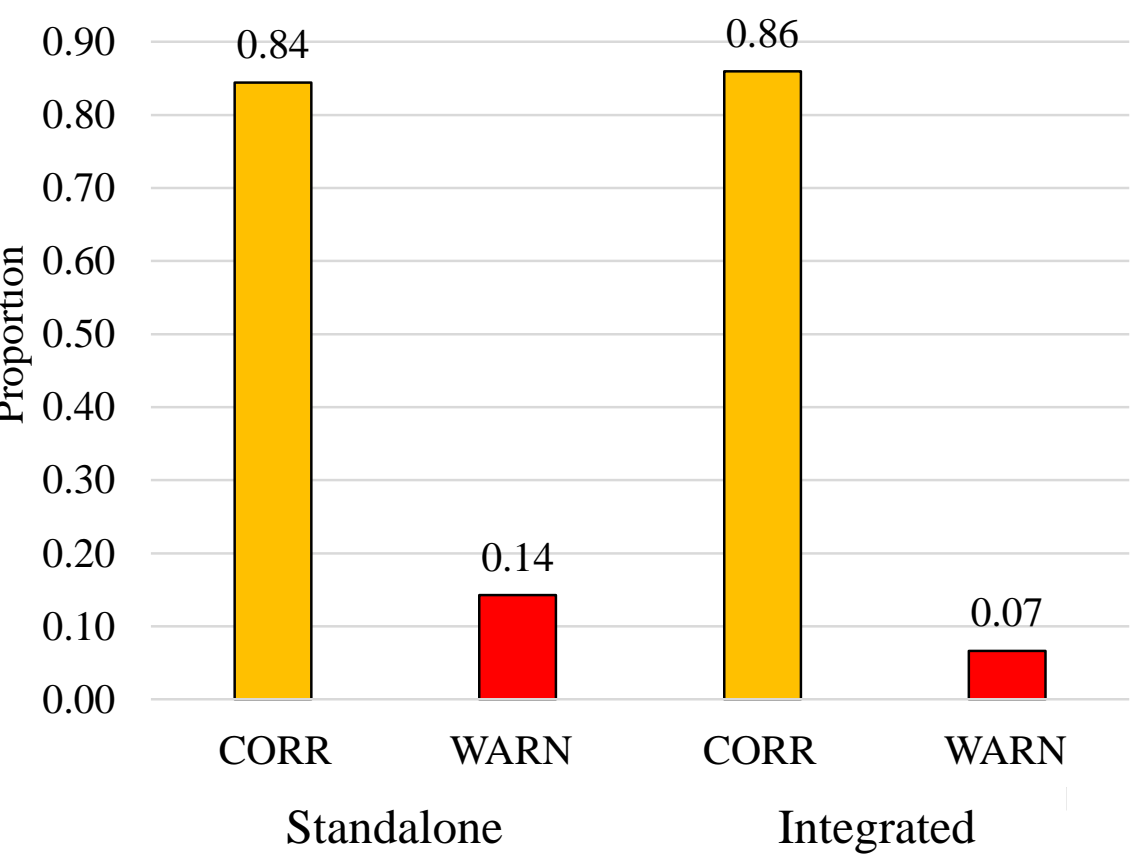

Proportion of Returns to Course with ATC Approval

1.00

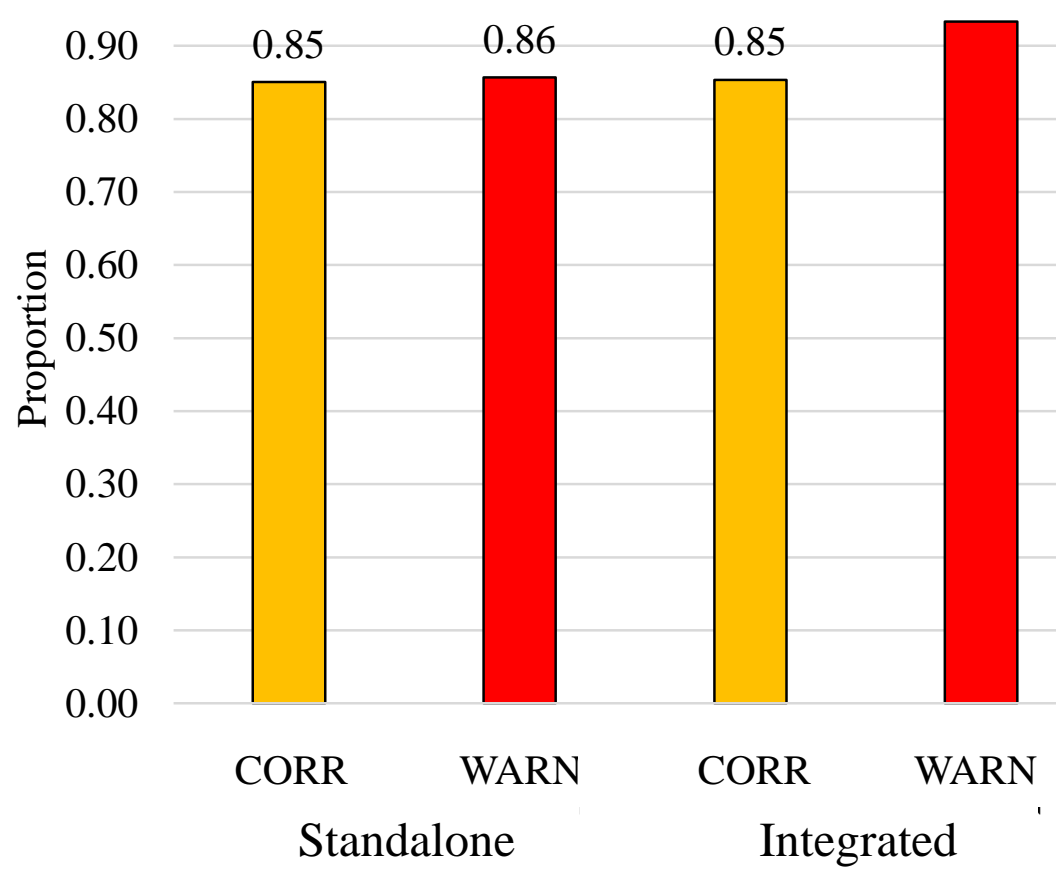




\section{Maneuver Statistics}

Maneuver Type

- Maneuver Preference

- Maneuver Size

- Lateral

- No substantial difference between display configurations on size of lateral maneuvers

- Vertical

- $18 \%$ of vertical maneuvers were $500 \mathrm{ft}$

- $\mathbf{8 2} \%$ were $1000 f t$

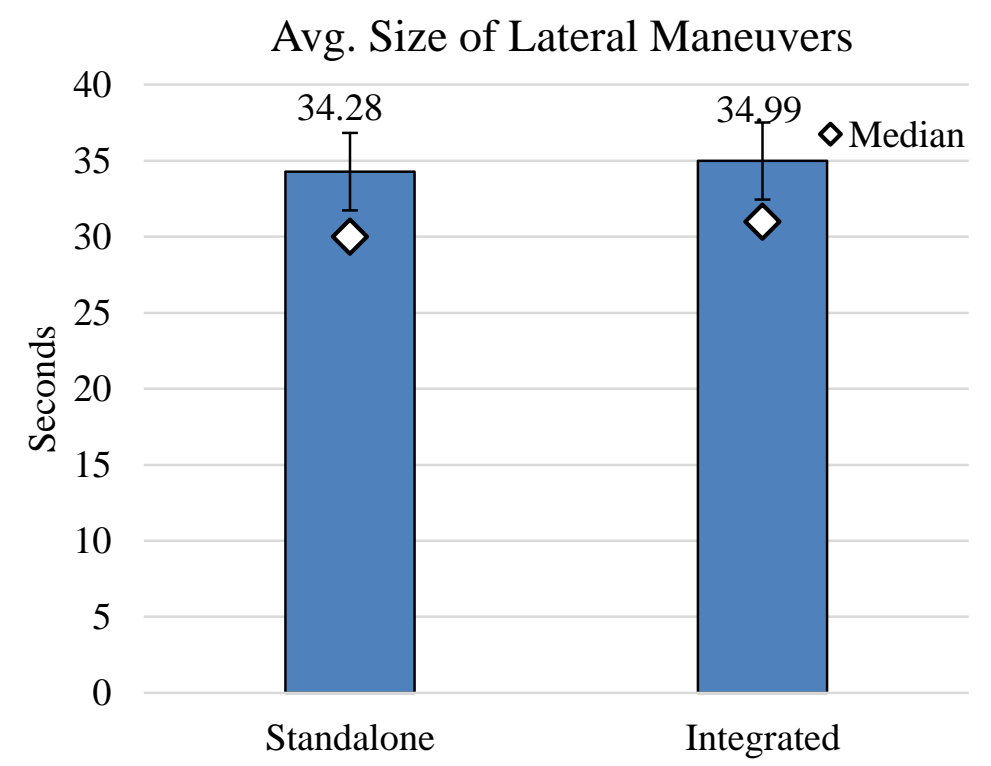

Display Configuration
- Descent

Level

Multiple
- Lateral maneuvers most common (61\%)

- Climbs more common than descents or level-ing off

$-<10 \%$ of the time pilots maneuvered in both dimensions
$7 \%$

$5 \%$

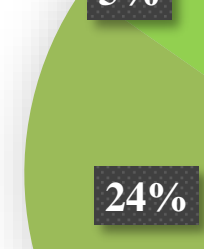

Climb

Right

Turn

\section{$32 \%$}

\section{$29 \%$}

urn

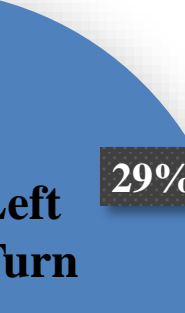




\section{Conclusions}

- Overall pilot performance was consistent with previous simulations when using minimum display, alerting \& guidance requirements

- On some measured response metrics performance was slightly better

- Proportions of LoWC virtually identical

- Standalone display resulted in little to no performance differences compared to the Integrated display configuration

* Data supports display, alerting \& guidance requirements as currently drafted

- Altitude tape needs to be on right side DAA display (frequently disregarded) and as close to the center of their field of view as possible

- In both the Standalone and Integrated conditions pilots uploaded a vertical maneuver that was no longer conflict-free according to DAA altitude bands

* Added requirement for placement of DAA vertical guidance 
- QUESTIONS? 